\title{
Influence of Rapid Solidification and Optimized Process Parameters on the Microstructural Evolution of Additive Manufactured Titanium Alloy Grade 5 Composite
}

\author{
O.S. Fatoba ${ }^{1 *} ;$ S.A. Akinlabi ${ }^{2} ;$ O.M. Ikumapayi ${ }^{1} ;$ E.T. Akinlabi ${ }^{3}$ \\ ${ }^{1}$ Department of Mechanical Engineering Science, University of Johannesburg, Johannesburg., South Africa. \\ ${ }^{2}$ Department of Mechanical Engineering, Walter Sisulu University, Butterworth Campus, Eastern Cape, South Africa. \\ ${ }^{3}$ Pan African University for Life and Earth Sciences Institute (PAULESI), Ibadan, Nigeria. \\ Corresponding Author: proffatobasameni@gmail.com*.
}

\begin{abstract}
The study experimentally investigates the effects that Ytterbium Laser System process parameters, such as laser power, powder feed rate and traverse speed, has on the resultant microstructure of Ti- $6 \mathrm{Al}-4 \mathrm{~V}$ grade 5 alloy. The deposition process was conducted employing a $3 \mathrm{~kW}(\mathrm{CW})$ Ytterbium Laser System (YLS-2000-TR) machine, coaxial to the reinforcement powder. The laser scanning speed and power were varied between the intervals of 1-1.2 $\mathrm{m} / \mathrm{min}$ and $900-1000 \mathrm{~W}$. All other parameters kept constant where the rate of gas flow, the spot diameter, and the rate of powder flow. The microstructure was characterized by grain size and morphology by using Optical Microscopy (OM) and Scanning Electron Microscopy (SEM). The microstructural and mechanical properties were ascertained and the relationships with the process parameters were achieved. As a result of rapid cooling, the morphological features of $\alpha$ and $\alpha$ are distinctive and appear acicular. The structures appear coarsened. The metallurgy of the samples identifies with a morphology of multi-scale; with the coarsened alpha structures being reduced, plate-like, discrete and finer. The alpha grains closer to the fusion zone grew epitaxially, and the ones above these are acicular and lamellar. The results also indicated that slow traverse speeds increase the scale of columnar grains, while other process parameters were kept constant. Columnar microstructures became prevalent due to the dynamic temperature gradients/spikes, and sustainable cooling rates, pertaining to fabricating direct laser deposited Ti-6Al-4V grade 5 alloy. It was ascertained that by increasing the traverse speeds, the cooling rates increased, which resulted in a decrease in the width of the columnar grains.
\end{abstract}

Keywords: Microstructure; Additive manufacturing; Titanium alloy; Process Parameters; Rapid Solidification

\section{Introduction}

Strength to weight ratio has been one of the factors used in substituting aluminium with titanium in recent times. Even though titanium is heavier than aluminium. The aerospace industry has been the main user of titanium initially, but other industries such as medical and automotive have harnessed the terrific properties of titanium also. The $(\alpha+\beta)$ titanium alloys constitute the combination of alpha and beta alloys. The alpha alloys that comprise of the $\alpha$-stabilisers provides $4-6 \%$ improvement in the strength of the material and the $\beta$ stabiliser elements facilitate in retaining the $\beta$-phase upon quenching from the $\beta$ or $(\alpha+\beta)$ phases. The conventional titanium grade alloy that is classified as an $(\alpha+\beta)$ alloy is Ti-6Al-4V and it is the most commonly used alloy in this category because it offers great versatile balance in properties that interests the aerospace industry to employ it widely in their applications $[1,2]$. The properties a titanium material possess is influenced significantly by the morphology of the microstructures. 
Titanium alloys have their microstructures described by how fine and coarse the structures appear and how the lamellar and equiaxed structures are arranged. These define the microstructural morphology of the $\alpha$ - and $\beta$ phases [3]. The various distinct microstructures of titanium and its alloys are promoted by the complex thermo-mechanical treatments that occur successively via homogenisation, deforming, recrystallizing and annealing to transfer internal stresses [4]. Fine microstructures improve the hardness, ductility, strength, plastic deformation and retard the nucleation and propagation of cracks [3].

AM techniques have leaped over conventional techniques due to the latter failure to produce multifaceted designs, contours and superior microstructures. Researchers around the globe have worked and published several surface modifications techniques but limitations still abound in terms of porosity, high cost, time consuming, and the metallurgical bond between the base metal and the reinforcements [5-9]. Laser metal deposition technique is established as a technique that can target the specific problem area rather than altering the whole component/structure. Developed properties will satisfy a greater scale of requirements for applications. Therefore, the fabricated composite will improve the service life of titanium alloy. Material has to be replaced or repaired after it has failed; this implicates more costs than anticipated. In light of this, solutions should be devised to minimize or eliminate material failure caused by the conditions and environment the material is exposed to. A.M is a viable technique that can be employed in the improvement of the properties of the material $[10,11]$. This study expands the additive manufacturing processes as a framework of how this research investigation can be tailored to produce good titanium alloy specimens, which can provide more durable, reliable and economical components when applied in various industrial applications.

\section{Methodology}

\subsection{Materials Specifications and Sample Preparation Method}

Titanium alloy grade $5(\mathrm{Ti}-6 \mathrm{Al}-4 \mathrm{~V})$ plates were used as substrates which had a volumetric dimension of $72 \times 72$ x $5 \mathrm{~mm}^{3}$. Prior to coating the materials, the substrates were sandblasted to remove the traces of dirt and other impurities. The residue of sand on the materials was washed with water, cleaned with acetone and air dried to facilitate in more absorption and less reflection of the laser beam which is irradiated onto the surface. The coatings were prepared at the National Laser Centre Council of Scientific and Industrial Research (NLC-
CSIR). The Laser Metal Deposition process is conducted using a 3kW (CW) Ytterbium Laser System (YLS-2000TR) machine which delivered the reinforcement powder into the created molten pool through a concentric nozzle, shielded and carried by Argon gas. The Kuka robot is used in operation with the laser. The particle sizes of the spherical reinforcement powders ranged between 50-150 $\mu \mathrm{m}$. The reinforcement powder used to create the coats composed of a ratio distribution of $\mathrm{Ti}-\mathrm{Al}-\mathrm{Si}-\mathrm{Cu}$ as follows: Ti-Al-11Si-5Cu, Ti-Al-12Si-2Cu; Ti-Al-13Si6Cu; Ti-Al-9Si-3Cu; Ti-Al-7Si-1Cu; Ti-Al-7Si-4Cu fractions correspondingly. Mixing of the reinforcements was done for 16hours in a Tubular mixer at a revolving pace of $72 \mathrm{rpm}$.

$2 \mathrm{~mm}$ separate the three co-axial nozzles and the titanium base metal. The conveying of the mixed homogeneous reinforcements was done via powder feeders at $2.0 \mathrm{~g} / \mathrm{min}$. The delivery was done with the protection assistance of the argon inert gas which was put at $2.5 \mathrm{~L} / \mathrm{min}$. The intersection of the multiple tracks was achieved at $70 \%$ overlap with a track length of $65 \mathrm{~mm}$. The optimal process parameters for the experiment was attained via the design of experiment (DOE). The samples fabrication was done with the optimal process parameters at $1.0-1.2 \mathrm{~m} / \mathrm{min}$ scan velocity and $900-1000$ $\mathrm{W}$ laser intensity. The mounted samples followed a grinding and polishing process by using the Struers Polishing Machine, which aided in the removal of resin that covered the surface of interest. The processes rendered the surface reflective and plane to carry out the desired material characterisation tests. The process was conducted based on the ASTM E3 - 11 standard. The cross-sectional microstructure of the LMD samples were observed by employing an optical microscope and scanning electron microscope. The purpose is to view the microstructure composition and morphology of the material after laser coating. The analyses of the samples were done by employing the TESCAN machine with an $\mathrm{X}$-MAX instrument to perform scanning electron microscopy (SEM) with electron dispersive spectroscopy (EDS) of the samples. EDS is to ascertain the elemental weights composed within the deposited clad. The analysis is conducted based on ASTM E76614e1, E986-04 and E1508-12a standards. The BX51M Olympus microscope is used to observe and intuitively study the resulting microstructural features (phase and morphology) of each LMD sample and an unprocessed substrate for baseline data. The microstructural examination is conducted under low and high magnification. The optical microscopy is based on the ASTM E2228-10 standard.

\section{Result and discussions}




\subsection{Microstructural Characterization}

Figures 1-6 are the optical macrographs of the samples which have enhanced the properties of the coatings. The micrographs display the deposited coating, HAZ and substrate. All the coatings of the specimens were manufactured by application of multiple tracks, hence the unevenness in the resulting coatings. The subsequent deposited tracks reheated the preceding track, which induced re-melting and re-solidification of the tracks. It is evident from the macrographs of all the samples that few cracks had initiated and propagated from the top of the deposit towards and terminating at the fusion line.
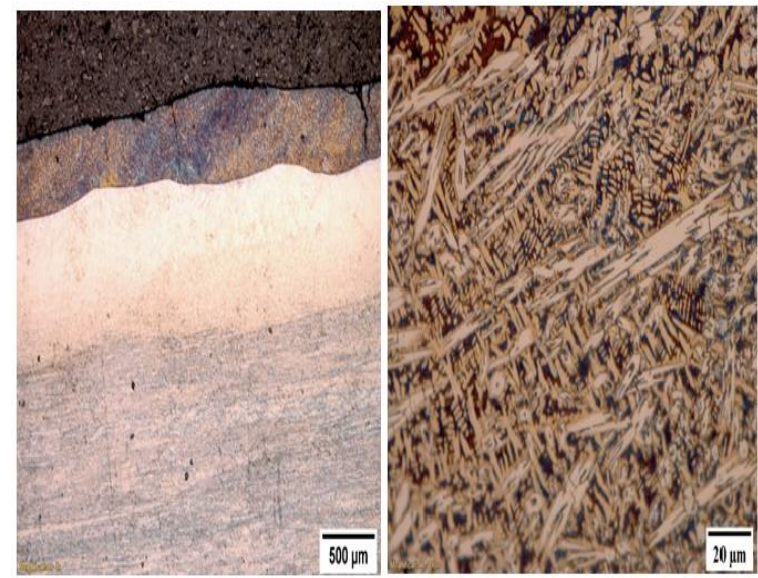

Fig 1: Optical Micrographs of Ti-Al-11 Si-5Cu at 900 $\mathrm{W}$ and $1.2 \mathrm{~m} / \mathrm{min}$

It appears that the cracks worsen in Figure 2. Cracks prevailed with some initiated at the centre of the deposit and propagated laterally, merging with other initiated cracks. This can be attributed to the variation in the wt. $\%$ of Silicon and Copper in the powder compositions; because of the difference in thermal expansion and specific heat capacities during the solidification process. This is substantiated by Erinosho et al. [12]. This phenomenon induced high thermal and residual stresses within the coatings of the samples. Moreover, this indicates that there was a difference in the shrinkage during solidification between the clad and the parent material. In addition, the samples which were fabricated at the maximum processing condition for each parameter $(1.2 \mathrm{~m} / \mathrm{min}$ scan speed, $1000 \mathrm{~W}$ laser intensity) generated a melt pool which solidified more rapidly than the minimum processing conditions $(1.0 \mathrm{~m} / \mathrm{min}$ scan speed, $900 \mathrm{~W}$ laser intensity). This also induced high tensile stresses in the clad. This correlates with the work done by Dai et al. [13].

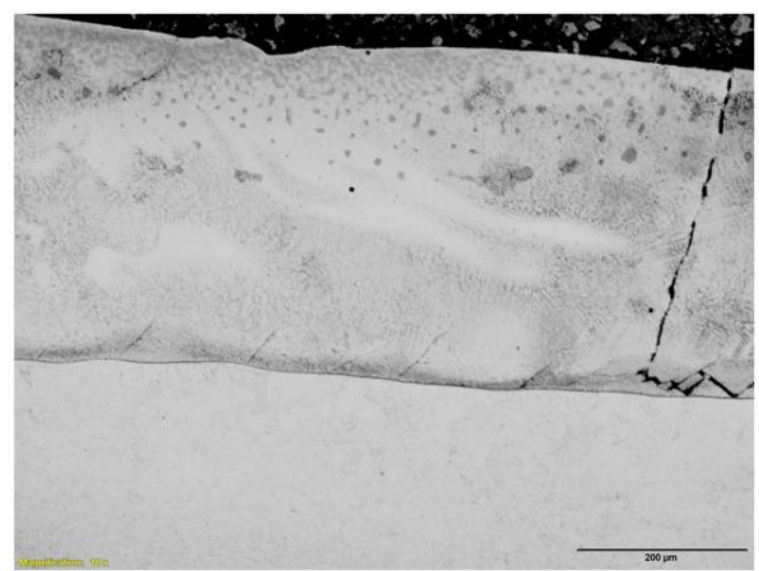

Fig 2: Optical Micrograph of Ti-Al-9Si-3Cu at $1000 \mathrm{~W}$ and $1.0 \mathrm{~m} / \mathrm{min}$

There are patches of indifferent colour on the coatings, which mostly appear greenish. Erinosho and Akinlabi [14] had stated that the presence of $\mathrm{Cu}$ in the composition of the powders provided the discolour. There appears to be visible gas entrapped porosities on the samples, which is attributed to the air being trapped in the coated layer because the rate of cooling was higher than the time for the air to escape the deposited layer [15]. The size of the gas entrapped pores is dependent on the turbulence in the molten pool during the deposition process, as the gas pores merge [16]. All the samples show a well-developed fusion zone. This indicates that there was sufficient alloying in the process and resulted in well metallurgical bonded clads, which Akinlabi et al. [17] claimed to have also found. The heat affected zone is clearly defined between the fusion line and the substrate in all samples as shown in Figure 4a. The substrate is a heat sink in the DLMD process, and the heat affected zone became noticeable because there was enough heat supplied conductively to the substrate to scantily promote microstructural alterations [18]. However, the microstructural modifications are not prominent in terms of grain growth. What is noticeable among the HAZ of all the samples is that fine $\alpha$ ' martensite structures had formed independently with most occurring right below the fusion line as shown in Figure 3. The formation of this type of microstructure provides great hardness values. The degree of occurrence of this phenomenon is influenced by coarse as-fabricated prior $\beta$ titanium grains since they provide great stability, thermodynamically, during high heat input [19]. Towards the fusion and HAZ (Figure 4a), the Widmanstätten structures become finer and well fused (Figure 4b); phases of $\alpha$-martensite are evident [14]. 


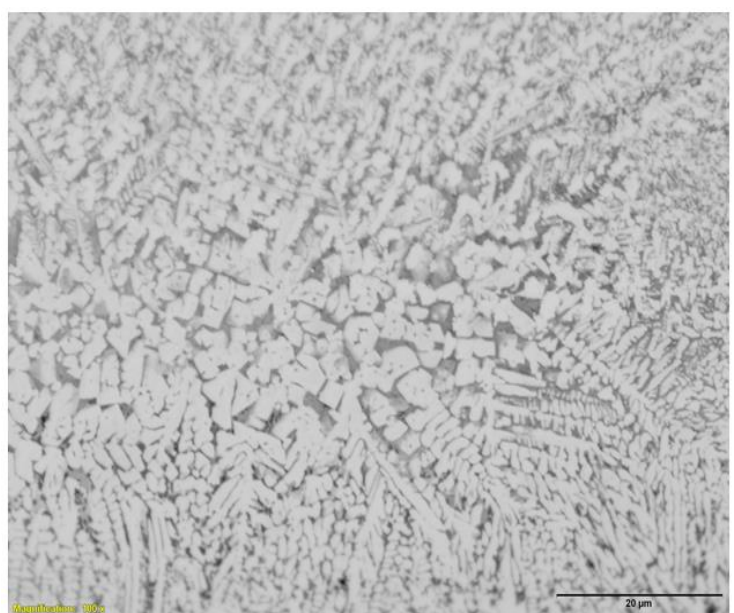

Fig 3: Optical Micrograph of Ti-Al-7Si-1Cu at $1000 \mathrm{~W}$, $1.2 \mathrm{~m} / \mathrm{min}$

These micrographs display the microstructural evolution resulting from the influence of processing conditions applied during the direct laser deposition process. The basic $\alpha+\beta$ microstructure of the Ti-6Al-4V parent material is seen to be influenced by the composite reinforcement powders and the processing conditions (Figures 3 and $4 \mathrm{~b}$ ). The microstructures of the samples are well-developed with coarsened $\alpha+\beta$ lamellae structures with clear globular alpha phases and noticeable prior-beta grain boundaries. As a result of rapid cooling, the morphological features of $\alpha$ and $\alpha$ ' are distinctive and appear acicular. The structures appear coarsened. Inconstancy with Yang et al. [20], the distinct acicular alpha phases and epitaxial growth of grains is in the attribution of the metallurgical characterization of the microstructure relative to the columnar prior-beta grain boundary

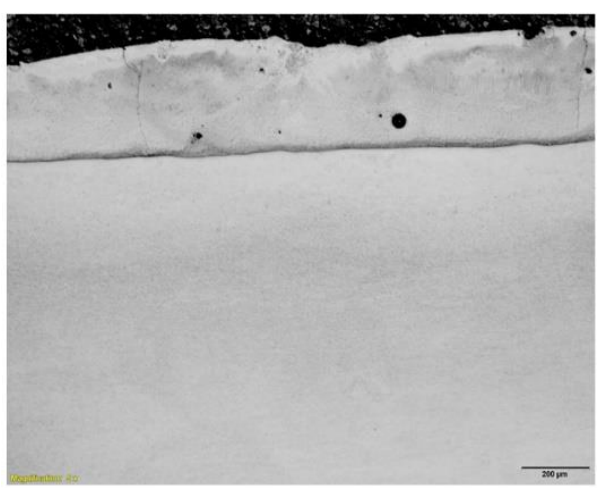

Fig 4a: Optical Micrograph of Ti-Al-12Si-2Cu at 900 $\mathrm{W}$ and $1.0 \mathrm{~m} / \mathrm{min}$

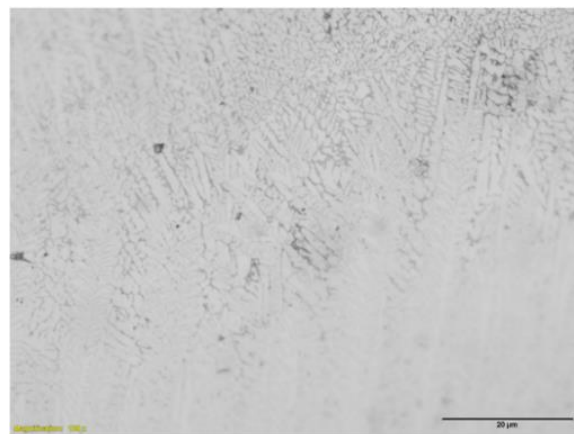

Fig 4b: Optical Micrograph of Ti-Al-12Si-2Cu at 900 $\mathrm{W}$ and $1.0 \mathrm{~m} / \mathrm{min}$

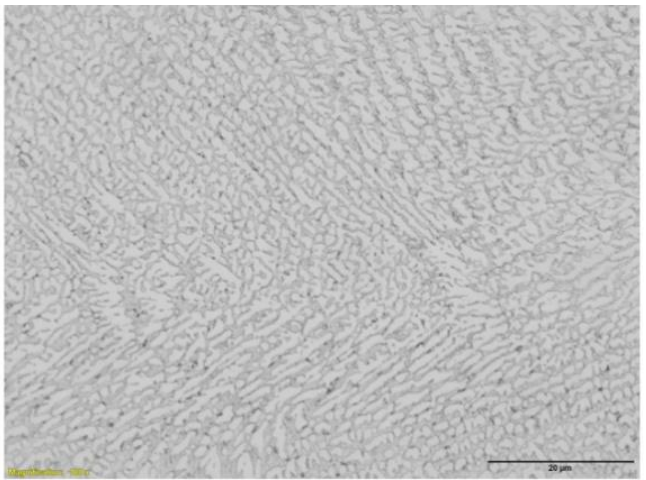

Fig 5: Optical Micrograph of Ti-Al-13Si-6Cu at $900 \mathrm{~W}$ and $1.2 \mathrm{~m} / \mathrm{min}$

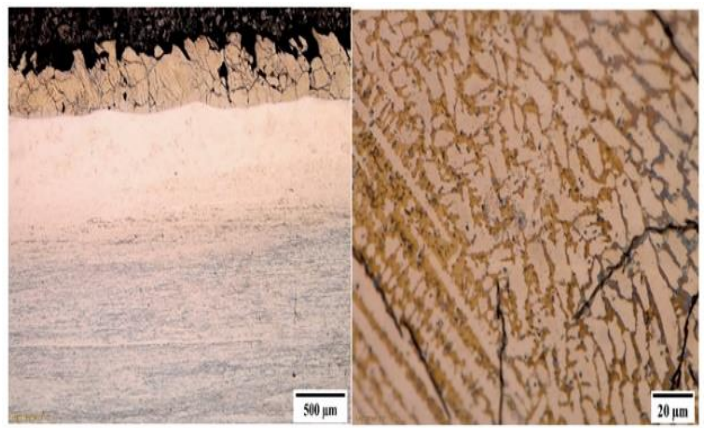

Fig 6: Optical Micrographs of Ti-Al-7Si-4Cu at $1000 \mathrm{~W}$ and $1.2 \mathrm{~m} / \mathrm{min}$

However, it does appear as though the primary alpha reduces significantly per volume fraction for most of the other samples observed. The metallurgy of the samples identifies with a morphology of multi-scale with the coarsened alpha structures being reduced, plate-like, discrete and finer as prominently seen in Figure 5. According to Erinosho and Akinlabi [21], these distinctive features of the alpha phase caused by varying cooling rates that evolved, the alpha phase morphology results in anisotropic mechanical properties. The primary alpha grains have secondary alpha Widmanstatten structures neighbouring them which Yang. et al. [20] also observed in their studies. The cooling rate influences the $\alpha$-phase morphology to be either equiaxed or acicular in the microstructure, which results in anisotropy in the mechanical properties [14]. Samples processed at 900- 
$1000 \mathrm{~W}$ laser intensity and speed of $1-1.2 \mathrm{~m} / \mathrm{min}$ coupled with the variations of silicon and copper contents had significant effects on the microstructures. Samples processed at a faster scanning speed resulted in a shorter laser material interaction time (LMIT). This increased the solidification rate. Therefore, more nucleation sites were promoted with the molten pool having a shorter time on the substrate before solidification. A higher scanning speed prompts the growth population of globular alpha phases [22].

\section{Conclusions}

1. The cooling rate influences the $\alpha$-phase morphology to be either equiaxed or acicular in the microstructure, which results in anisotropy in the mechanical properties.

2. Cracks prevailed with some initiated at the centre of the deposit and propagated laterally, merging with other initiated cracks. This can be attributed to the variation in the wt.\% of Silicon and Copper in the powder compositions, because of the difference in thermal expansion and specific heat capacities during the solidification process.

3. The microstructural modifications are not prominent in terms of grain growth. What is noticeable among the HAZ of all the samples is that fine $\alpha$ ' martensite structures had formed independently with most occurring right below the fusion line. The formation of this type of microstructure provides great hardness values. The degree of occurrence of this phenomenon is influenced by coarse as-fabricated before $\beta$ titanium grains since they provide great stability thermodynamically during high heat input.

\section{Acknowledgements}

The authors wish to acknowledge Pan African University for Life and Earth Sciences (PAULESI), Ibadan, Nigeria for the funding and National Laser Center, CSIR South Africa for the laser equipment.

\section{References}

[1] Fatoba, O.S., Akinlabi, E.T., Akinlabi, S.A., Numerical Investigation of Laser Deposited AlBased Coatings on Ti-6Al-4V Alloy. 2018 IEEE 9th International Conference on Mechanical and Intelligent Manufacturing Technologies 85 (2018) doi: 10.1109/ICMIMT.2018.8340426.

[2] Fatoba O.S., Akinlabi S.A., Gharehbaghi R., Akinlabi E.T (2018). Microstructural Analysis, Microhardness and Wear Resistance Properties of Quasicrystalline Al-Cu-Fe Coatings on Ti-6Al-4V Alloy. Materials Express Research. 5(6), 1-14. https://doi.org/10.1088/2053-1591/aaca70.
[3] C. Leyens and M. Peters, Titanium And Titanium Alloys, Fundamentals And Applications., WILEYVCH Verlag GmbH \& Co. KGaA, Weinheim, ISBN: 3-527-30534-3, 2003.

[4] J. Williams and G. Lutjering, "Chapter 5: Alpha+Beta Alloys," Titanium, pp. 178-232, 2003.

[5] Adesina O.S; Popoola A.P.I; Fatoba O.S., Laser Surface Modification-A focus on the Wear Degradation of Titanium Alloy, InTech (2016), DOI: http://www.intechopen.com/books/fiber-laser/

[6] Fatoba O.S., Adesina O.S. Popoola A.P.I., The International Journal of Advanced Manufacturing Technology. 97(5), 2341 (2018)

[7] Gharehbaghi, R., Fatoba, O.S., Akinlabi, E.T. International Conference on Mechanical and Intelligent Manufacturing Technologies, 31 doi: 10.1109/ICMIMT.2018.8340416. (2018)

[8] Fu, Y., Zhang, X.-C., Sui, J.-F., Tu, S.-T., Xuan, F.Z. \& Wang, Z.-D., Optics \& Laser Technology, 67(1), 78 (2015)

[9] Weng, F., Chen, C. \& Yu, H. (2014a). Research status of laser cladding on titanium and its alloys: a review. Materials \& Design, 58:412-425.

[10]Fatoba O.S; Akinlabi, E.T., Makhatha, M.E. Materials Today: Proceedings. 5(9), 18368 (2018)

[11] M.C. Obiegbu; O.S. Fatoba; E.T. Akinlabi., S.A. Akinlabi Materials Express Research, 6(4) 1 (2019)

[12] M. F. Erinosho, E. T. Akinlabi, O. Johnson and G. Owolabi, Effect Of Scanning Speed On The Material Characterisation Of Laser Deposited Titanium Alloy And Copper, (2015)

[13] J. Dai, F. Zhang, A. Wang, H. Yu and C. Chen, "Microstructure And Properties Of Ti-Al Coating And Ti-Al-Si System Coatings On TI-6Al-4V," Surface \& Coatings Technology, (2017)

[14] M. F. Erinosho and E. T. Akinlabi, Effect Of Laser Power On The Microstructural Behaviour And Strength Of Modified Laser Deposited Ti6Al4V+Cu Alloy For Medical Application, Johannesburg: Department Of Mechanical Engineering Science, University Of Johannesburg, (2015)

[15] G. Yuan, Z. Li, Y. Lou and X. Zhang, Materials Science And Engineering A, 280, 108 (2000)

[16] R. M. Mahamood, E. T. Akinlabi, M. Shukla and S. Pityana, Proceedings of The International MultiConference of Engineers And Computer Scientists, (2014)

[17]E. Akinlabi, M. A. Tayob and F. Pietra, "Experimental And Numerical Analysis Of Geometrical Properties Of Laser Metal Deposited Titanium," 25, 1 (2016)

[18] R. M. Mahamood, E. T. Akinlabi, M. Shukla and S. Pityana, Proceedings of The International MultiConference Of Engineers And Computer Scientists, (2013) 
[19] T. Wang, Y. Zhu, S. Zhang, H. Tang and H. Wang, "Grain Morphology Evolution Behavior Of Titanium Alloy Components During Laser Melting Deposition Additive Manufacturing," Journal of Alloys And Compounds, 632, 505 (2015)

[20] Y. Yang, Y. Liu, J. Chen, H. Wang, Z. Zhang, Y. $\mathrm{Lu}, \mathrm{S} . \mathrm{Wu}$ and J. Lin, Materials Science \& Engineering A, 707, 548 (2017)

[21] M. F. Erinosho and E. T. Akinlabi, "Influence Of Laser Power On The Surfacing Microstructures And Microhardness Properties Of Ti-6Al-4V-Cu Alloys Using The Ytterbium Fiber Laser," (2016)

[22]R. M. Mahamood and E. T. Akinlabi, 6th International Conference Of Materials Processing And Characterization, (2016) 